CASE REPORT

\title{
Primary mucosa-associated lymphoid tissue (MALT) lymphoma of the trachea: a case of surgical resection and long term survival

\author{
K Okubo, N Miyamoto, C Komaki
}

Thorax 2005;60:82-83. doi: 10.1136/thx.2003.018721

Primary malignant lymphoma of the trachea is rare. The case history is presented of a 44 year old woman with a mucosaassociated lymphoid tissue (MALT) lymphoma of the trachea who was treated with a tracheal resection and reconstruction. The patient has been free from the disease for 53 months, which confirms the favourable prognosis of MALT lymphoma following local treatment.

$\mathrm{S}$ ince Isaacson and Wright described extranodal lymphomas arising from mucosa-associated lymphoid tissue (MALT), ${ }^{1}$ the literature has reported a relatively favourable prognosis of this entity with different therapeutic approaches to specific sites. ${ }^{2}$ Some primary pulmonary lymphomas used to be termed "pseudolymphoma" with a favourable prognosis ${ }^{3}$ which was misleading. Immunohistochemistry and the formulation of the MALT lymphoma concept led to the disappearance of the pseudolymphoma. MALT lymphoma of the trachea is extremely rare and there are insufficient data on its prognosis. We present a patient with MALT lymphoma of the trachea in whom surgical resection resulted in long term survival.

\section{CASE REPORT}

A 44 year old woman with no history of smoking presented with exertional dyspnoea. Bronchofibreoscopy identified a tracheal stenosis and she was referred to our hospital for further management. Apart from the dyspnoea she felt well. She had no symptoms of Sjoegren's syndrome or other autoimmune disorders. On physical examination there was no clubbing, lymphadenopathy, or hepatosplenomegaly. Chest radiography and a laminagram showed narrowing of the thoracic trachea (fig lA), and a chest CT scan showed a mass protruding into the tracheal lumen. Pulmonary function tests showed a vital capacity of $2.52 \mathrm{l}$ (97\% of predicted) and forced expiratory volume in 1 second of $1.08 \mathrm{l}$. Blood counts and chemistry were all within normal limits and electrophoretic analysis of the components of the serum proteins showed a normal pattern without any broad peaks in the $\gamma, \beta_{2}$, or $\alpha_{2}$ globulin regions. No microorganisms were seen on sputum culture. Fibreoptic bronchoscopy showed an intratracheal polypoid lesion originating from the left side of the trachea (fig 1B). The lesion was proximally located on the 10th cartilaginous ring of the trachea and attached to one third of the inner circumferential lumen. Bronchoscopic biopsy failed to establish a pathological diagnosis. Systemic screening including CT scans of the chest, abdomen and brain, a bone scan, and gallium-citrate scintigraphy found no other abnormal lesions. Because of the airway stenosis and the limitation of the longitudinal extension of the disease, the patient underwent a tracheal resection and
Figure 1 (A) Laminagram showing a mass protruding into the tracheal lumen. (B) Bronchoscopic view showing an intratracheal polypoid lesion attached to one third of the circumferential lumen. 


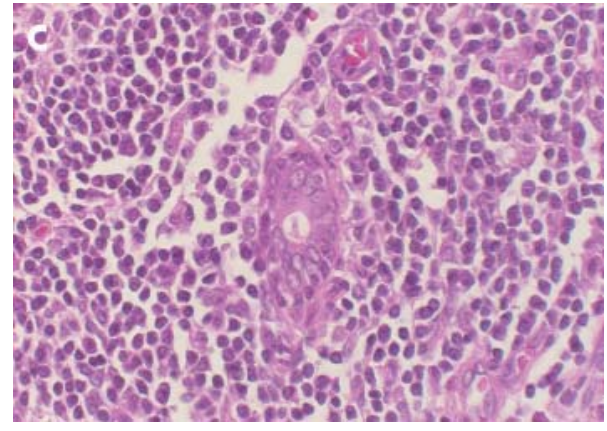

Figure 2 Microscopic appearance of the resected tumour (haematoxylin-eosin stain, $\times 100$ ).

reconstruction. The trachea was circumferentially divided proximal and distal to the tumour by median sternotomy of the upper region, and the affected portion of the trachea of six cartilaginous rings $(3.0 \mathrm{~cm})$ was resected. After frozen sections of the stumps were confirmed not to be malignant, the ends of the trachea were anastomosed with absorbable sutures (4-0 Vicryl). No paratracheal lymphadenopathy was identified.

Histological examination showed a diffuse infiltrate of lymphocytes and centrocyte-like cells surrounding reactive follicles, with plasmacytoid differentiation in the mucosal surface. Small lymphocytes invaded the epithelial structures of the glands forming lymphoepithelial lesions (fig 2). The malignant cells expressed CD45 and CD20, indicating an increase of $\mathrm{B}$ cells with a reactive response. CD5 and CD10 were negative. Anti-kappa and lambda light chain staining showed no apparent monoclonality. Although the immunohistochemical stain was inconclusive, the final diagnosis was a low grade, B cell MALT lymphoma. The postoperative course was uneventful and the patient has been well without any symptoms of recurrence for 53 months.

\section{DISCUSSION}

Primary tracheal tumours are rare. ${ }^{4}$ Squamous cell carcinoma and adenoid cystic carcinoma together comprise about $75 \%$ of all primary tracheal tumours in similar numbers. A wide variety of tumours of other histology - most often benign or of low grade malignancy-comprise the remaining 25\% of tracheal tumours. Operability for primary malignant tracheal tumours depends on the extent of the tumour. In the largest series of primary tracheal tumours reported by Grillo and Mathisen $(\mathrm{n}=198),{ }^{5} 74 \%$ were excised during a period of 26 years.

MALT lymphomas were first described by Issacson and Wright in 1983 in a small series of patients with low grade B cell gastrointestinal lymphomas. ${ }^{1}$ Although MALT lymphomas-extranodal lymphomas arising from MALT-occur most frequently in the stomach, they have also been described at various non-gastrointestinal sites. MALT lymphomas are characterised by neoplastic marginal cells which display a variable combination of colonisation of reactive germinal centres, plasma differentiation, and destructive epithelial infiltration forming lymphoepithelial lesions. Immunohistochemical examination often shows the characteristic B cell lymphoma with monoclonal expansion by monotypic cytoplasmic immunoglobulin. This low grade malignancy has a tendency to remain localised to the primary site and to respond favourably to local treatments such as surgery and/or radiotherapy. The outcome and prognosis for MALT lymphomas are more favourable than for other extranodal lymphomas reported in the literature. ${ }^{26}$

As this entity has only recently been delineated, there are insufficient data on the prognosis of MALT lymphoma of the trachea. In the largest series of non-gastrointestinal MALT lymphomas reported to date $(\mathrm{n}=75),{ }^{2}$ there was only one patient with MALT lymphoma of the trachea. A few cases of local treatment of MALT lymphomas of the trachea have been reported in the English language literature but none has studied the long term outcome. ${ }^{7-9}$ A report in 1981 of a tracheal lymphoma treated by surgical resection which resulted in survival for more than 5 years was probably a MALT lymphoma. ${ }^{10}$

As our patient presented with a symptomatic stenosis of the airway, we performed a tracheal resection and end to end reconstruction without a preoperative pathological diagnosis. Pathological examination revealed a primary lymphoma of the trachea, so the strategy of local treatment for MALT lymphoma was justified. The patient has survived for more than 4 years without recurrence, which suggests that local treatment of the condition has a favourable prognosis.

\section{Authors' affiliations \\ K Okubo, N Miyamoto, C Komaki, General Thoracic Surgery, Gifu National Hospital, Japan}

Correspondence to: Dr K Okubo, General Thoracic Surgery, Gifu National Hospital, Japan, 5-1-1 Hinohigashi, Gifu 500-8718 Japan; okubo@gifu.hosp.go.jp

Received 11 November 2003

Accepted 11 February 2004

\section{REFERENCES}

1 Isaacson P, Wright DH. Malignant lymphoma of mucosa-associated lymphoid tissue: a distinctive type of B-cell lymphoma. Cancer 1983;52:1410-6.

2 Zinzani PL, Magagnoli M, Galieni P, et al. Nongastrointestinal low-grade mucosa-associated lymphoid tissue lymphoma: analysis of 75 patients. J Clin Oncol 1999; 17:1254-8.

3 Saltzstein SL. Pulmonary malignant lymphomas and pseudolymphomas: classification, therapy and prognosis. Cancer 1963;16:928-55.

4 Fidias $\mathrm{P}$, Wright C, Harris NL, et al. Primary tracheal non-Hodgkin's lymphoma. A case report and review of the literature. Cancer 1996;77:2332-8

5 Grillo HC, Mathisen DJ. Primary tracheal tumors: treatment and results. Ann Thorac Surg 1990;49:69-77.

6 Thieblemont C, Bastion Y, Berger F, et al. Mucosa-associated lymphoid tissue gastrointestinal and nongastrointestinal lymphoma behavior: analysis of 108 patients. J Clin Oncol 1997;15:1624-30.

7 Wiggins J, Shefield E, Green M. Primary B cell malignant lymphoma of the trachea. Thorax 1988;43:497-8.

8 Kaplan MA, Pettit CL, Zukerberg LR, et al. Primary lymphoma of the trachea with morphologic and immunophenotypic characteristics of low-grade B-cell lymphoma of mucosa-associated lymphoid tissue. Am J Surg Pathol 1992;16:71-5.

9 Tsurutani J, Konishita A, Kaida $\mathrm{H}$, et al. Bronchoscopic therapy for mucasaaassociated lymphoid tissue lymphoma of the trachea. Intern Med 1999;38:276-8.

10 Maeda M, Kotake Y, Monden Y, et al. Primary malignant lymphoma of the trachea. Report of a case successfully treated by primary end-to-end anastomosis after circumferential resection of the trachea. J Thorac Cardiovasc Surg 1981;81:835-9. 